\title{
Free-Radical Reaction of the Iron(II) Dichloroclathrochelate with Tetrahydrofuran Radical Derivatives: Synthesis and Structure of the Monotetrahydrofuryl-Containing Cage Complex
} \author{
and Yan Z. Voloshin ${ }^{\mathrm{c}}$ \\ ${ }^{a}$ Nikolaev Institute of Inorganic Chemistry SB RAS, 630090 Novosibirsk, Russia \\ ${ }^{\mathrm{b}}$ Novosibirsk State University, 630090 Novosibirsk, Russia \\ ${ }^{\mathrm{c}}$ A.N. Nesmeyanov Institute of Organoelement Compounds RAS, 110991 Moscow, Russia \\ ${ }^{\circledR}$ Corresponding authorE-mail: lscc@niic.nsc.ru
}

Mikhail A. Vershinin, ${ }^{\mathrm{a}}$ Alexey B. Burdukov, ${ }^{\mathrm{a} @}$ Natalie V. Pervukhina, ${ }^{\mathrm{a}}$ Ilia V. Eltsov, ${ }^{\mathrm{b}}$

\begin{abstract}
Free-radical substitution of the chlorine atoms in the fluoroboron-capped iron(II) dichloroclathrochelate with tetrahydrofuran radical derivatives was studied. The reaction proceeds with high regioselectivity and yields the monofunctionalized macrobicyclic product. The molecular structure of this complex was determined both in solution and in the solid state using multinuclear NMR and the single-crystal X-ray diffraction.
\end{abstract}

Keywords: Iron complexes, clathrochelates, ligand reactivity, radical substitution, X-ray crystallography, NMR spectroscopy

\section{Introduction}

Recently, we have reported the first observation of the free-radical substitution of the ribbed chlorine atoms of the boron-capped tris-dioximate iron(II) dichloroclathrochelate (Scheme 1) via its interaction with 1,4-dioxane radical derivatives. This reaction mainly afforded the mono- and bis-1,4-dioxan-2-yl-substituted iron(II) macrobicyclic complexes. ${ }^{[1]}$ This paper describes a similar reaction of the tetrahydrofuryl radical, as well as the structure of the major monosubstituted tetrahydrofuryl-containing clathrochelate product (both in solution and in the solid state) and its spectral characteristics.

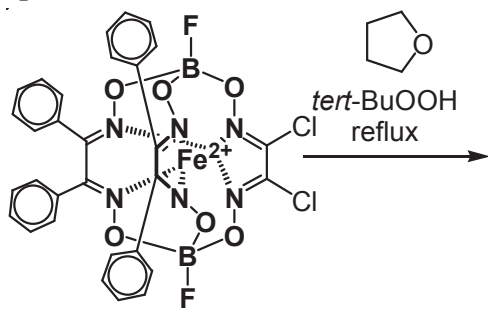

$\mathrm{FeBd}_{2}\left(\mathrm{Cl}_{2} \mathrm{Gm}\right)(\mathrm{BF})_{2}$

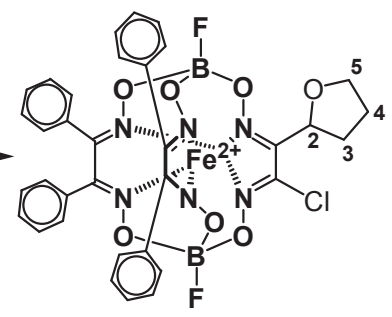

$\mathrm{FeBd}_{2}(\mathrm{Cl}(\mathrm{THF}) \mathrm{Gm})(\mathrm{BF})_{2}$
Scheme 1.

\section{Experimental}

The ${ }^{1} \mathrm{H},{ }^{11} \mathrm{~B},{ }^{19} \mathrm{~F}$ and ${ }^{13} \mathrm{C}\left\{{ }^{1} \mathrm{H}\right\}$ NMR spectra of the complex obtained were recorded from its $\mathrm{CD}_{2} \mathrm{Cl}_{2}$ solution with a Bruker Avance III 500 spectrometer (working frequencies $500.13\left({ }^{1} \mathrm{H}\right)$, $160.46\left({ }^{11} \mathrm{~B}\right), 470.59\left({ }^{19} \mathrm{~F}\right)$, and $\left.125.76 \mathrm{MHz}\left({ }^{13} \mathrm{C}\right)\right)$. The ${ }^{1} \mathrm{H}$ and ${ }^{13} \mathrm{C}$ NMR chemical shifts are given in the $\delta$ scale and referred to residual proton signals of the solvent $\left(5.34 \mathrm{ppm}\right.$ for $\mathrm{CHDCl}_{2}$ and $53.8 \mathrm{ppm}$ for $\mathrm{CD}_{2} \mathrm{Cl}_{2}$ ), the signal assignment in the corresponding spectra and structure determination were carried out on the basis of 2D COSY,
HMBC and HSQC NMR spectra. The ${ }^{11} \mathrm{~B}$ and ${ }^{19} \mathrm{~F}$ NMR chemical shifts are referred to external $\mathrm{BF}_{3} \cdot \mathrm{O}\left(\mathrm{C}_{2} \mathrm{H}_{5}\right)_{3}$ and TFT. ${ }^{1} \mathrm{H}$ spin-spin coupling constants in the tetrahydrofuryl fragment and chemical shifts in the ${ }^{1} \mathrm{H}$ NMR spectrum were determined by simulation of the spin system with NUMMRIT algorithm and the method of totallineshape fitting (RMS $=0.1357, \mathrm{R}=0.0067$, SpinWorks 3.1.8., Bruker Topspin 2.1).

The clathrochelate precursor $\mathrm{FeBd}_{2}\left(\mathrm{Cl}_{2} \mathrm{Gm}\right)(\mathrm{BF})_{2}$ was obtained as described in ${ }^{[2]}$.

Synthesis

1,8-Bis(2-fluorobora)-2,7,9,14,15,20-hexaoxa3,6,10,13,16,19-hexaaza-4,5,11,12-tetraphenyl-17-chloro-18-(2tetrahydrofuryl)bicyclo[6.6.6]eicosa-3,5, 10,12,16,18-hexaen(2-) iron $(2+), \mathrm{FeBd}_{2}(\mathrm{Cl}(\mathrm{THF}) \mathrm{Gm})(\mathrm{BF})_{2}$ (a typical procedure).

Complex $\mathrm{FeBd}_{2}\left(\mathrm{Cl}_{2} \mathrm{Gm}\right)(\mathrm{BF})_{2} \quad(0.100 \mathrm{~g}, \quad 0.13 \mathrm{mmol})$ was dissolved in THF $(20 \mathrm{ml})$, and $5.5 \mathrm{M}$ solution of tertbutylhydroperoxide in decane $(0.7 \mathrm{ml})$ was added. The reaction mixture was refluxed for $2 \mathrm{~h}$ and left overnight. Then an additional portion of the tert-butylhydroperoxide solution $(0.5 \mathrm{ml})$ was added, and the reaction mixture was refluxed for $2 \mathrm{~h}$; the reaction course was monitored by TLC $\left(\mathrm{SiO}_{2}\right.$ foil, eluent: chloroform - hexane 2:1 mixture). Then the reaction mixture was rotary evaporated to dryness and the solid residue was extracted with chloroform. The extract was purified by column chromatography (column: $1 \times 20 \mathrm{~cm}$, $\mathrm{SiO}_{2}$, eluent: chloroform). The head elute, containing mainly the clathrochelate precursor, was thrown out, and the second elute was collected. This elute was evaporated to dryness and recrystallized from dichloromethane - heptane 1:2 mixture. Yield: $0.053 \mathrm{~g}(50 \%)$. Calculated, \%: C 52.1, H 3.5, N 10.7. $\mathrm{C}_{34} \mathrm{H}_{27} \mathrm{~N}_{6} \mathrm{O}_{7} \mathrm{ClB}_{2} \mathrm{~F}_{2} \mathrm{Fe}$. Found, \%: C 52.1, H 3.7, N 10.5. ${ }^{1} \mathrm{H}$ NMR $\left(\mathrm{CD}_{2} \mathrm{Cl}_{2}\right) \delta$ ppm: $2.12(\mathrm{~m}, 1 \mathrm{H}$, $\left.\mathrm{C}^{4} H_{2}\right), 2.23\left(\mathrm{~m}, 2 \mathrm{H}, \mathrm{C}^{4} \mathrm{H}_{2} \mathrm{C}^{3} \mathrm{H}_{2}\right), 2.43\left(\mathrm{~m}, 1 \mathrm{H}, \mathrm{C}^{3} \mathrm{H}_{2}\right), 4.01$ (td, $\left.1 \mathrm{H}, \mathrm{C}^{5} \mathrm{HO}\right), 4.19$ (td, $\left.1 \mathrm{H}, \mathrm{C}^{5} \mathrm{H}_{2} \mathrm{O}\right), 5.66\left(\mathrm{t}, 1 \mathrm{H}, \mathrm{C}^{2} H \mathrm{O}\right), 7.38(\mathrm{~m}$, $20 \mathrm{H}, \mathrm{Ph}) \cdot{ }^{13} \mathrm{C}\left\{{ }^{1} \mathrm{H}\right\} \operatorname{NMR}\left(\mathrm{CD}_{2} \mathrm{Cl}_{2}\right) \delta \mathrm{ppm}: 27.30\left(\mathrm{~s}, \mathrm{C}^{4} \mathrm{H}_{2}\right), 30.88(\mathrm{~s}$, $\left.\mathrm{C}^{3} \mathrm{H}_{2}\right), 70.22\left(\mathrm{~s}, \mathrm{C}^{5} \mathrm{H}_{2}\right), 73.65\left(\mathrm{~s}, \mathrm{C}^{2} \mathrm{H}\right), 128.4$ (s, 2-C (Ph)), 129.4 (s, 1-C (Ph)), $130.7(\mathrm{~s}, 4-\mathrm{C}(\mathrm{Ph})), 130.9(\mathrm{~s}, 3-\mathrm{C}(\mathrm{Ph})), 132.28(\mathrm{~s}$, $\mathrm{Cl} C=\mathrm{N}), 157.38,157.53$, (two $\mathrm{s}, \mathrm{PhC}=\mathrm{N}), 157.71(\mathrm{~s},(\mathrm{THF}) \mathrm{C}=\mathrm{N})$. 
Table 1. Proton spin coupling parameters for the tetrahydrofuryl fragment

\begin{tabular}{|c|c|c|c|c|c|c|c|}
\hline & \multicolumn{6}{|c|}{$J, \mathrm{~Hz}$} & \multirow[t]{2}{*}{$\delta, \mathrm{ppm}$} \\
\hline & $\mathrm{C}^{5} H^{1}$ & $\mathrm{C}^{5} H^{2}$ & $\mathrm{C}^{3} H^{1}$ & $\mathrm{C}^{3} H^{2}$ & $\mathrm{C}^{4} H^{1}$ & $\mathrm{C}^{4} H^{2}$ & \\
\hline $\mathrm{C}^{2} \mathrm{H}$ & 0.02 & -0.07 & 7.41 & 8.68 & -0.34 & -0.24 & 5.66 \\
\hline $\mathrm{C}^{5} H^{1}$ & & -8.01 & -0.21 & 0.04 & 6.56 & 8.05 & 4.19 \\
\hline $\mathrm{C}^{5} \mathrm{H}^{2}$ & & & 0.16 & 0.40 & 4.60 & 7.76 & 4.02 \\
\hline $\mathrm{C}^{3} H^{1}$ & & & & -12.41 & 3.97 & 7.84 & 2.43 \\
\hline $\mathrm{C}^{3} H^{2}$ & & & & & 8.19 & 9.02 & 2.22 \\
\hline $\mathrm{C}^{4} H^{1}$ & & & & & & -12.24 & 2.25 \\
\hline $\mathrm{C}^{4} H^{2}$ & & & & & & & 2.11 \\
\hline
\end{tabular}

Proton spin coupling parameters for the tetrahydrofuryl fragment are listed in Table 1. ${ }^{11} \mathrm{~B}$ NMR $\delta$ ppm: $3.56\left(\mathrm{~d}, J_{11_{B-}{ }_{19}}=16 \mathrm{~Hz}\right), 3.62$ $\left(\mathrm{d}, J_{1 l_{B-} 19_{\mathrm{F}}}=15 \mathrm{~Hz}\right) .{ }^{19} \mathrm{~F}$ NMR $\delta$ ppm: -169.37 (q), -169.50 (q). IR $v$ $\mathrm{cm}^{-1}$ : 692, 925, 1063, 1108, $1169 v(\mathrm{~N}-\mathrm{O}), 1215 \mathrm{~m} v(\mathrm{~B}-\mathrm{O})+\mathrm{v}(\mathrm{B}-\mathrm{F})$, $1360,1444 \delta(\mathrm{C}-\mathrm{H}), 1547 \mathrm{~m} v(\mathrm{ClC}=\mathrm{N}), 1578 \mathrm{w} v(\mathrm{PhC}=\mathrm{N}), 2876 \mathrm{w}$, 3059w v(C-H).

\section{X-ray crystallography}

Single crystals of the complex $\mathrm{FeBd}(\mathrm{Cl}(\mathrm{THF}) \mathrm{Gm})$ $(\mathrm{BF})_{2} \cdot 2.2 \mathrm{CH}_{2} \mathrm{Cl}_{2}$ suitable for the $\mathrm{X}$-ray crystallography were grown by slow evaporation of its saturated solution in dichloromethaneheptane 1:2 mixture at room temperature. The crystal system of $\mathrm{C}_{36.30} \mathrm{H}_{31.60} \mathrm{~B}_{2} \mathrm{Cl}_{5.60} \mathrm{~F}_{2} \mathrm{FeN}_{6} \mathrm{O}_{7}(M=977.87)$ is orthorhombic at $293 \mathrm{~K}: a=15.7330(10), b=16.6740(9), c=17.0570(9) \AA, V=$ 4474.6(4) $\AA^{3}$, space group $P 2{ }_{1}{ }_{1}{ }_{1}, Z=4, d_{\text {calc }}=1.452 \mathrm{~g} \mathrm{~cm}^{-3}$. The intensities of 19891 reflections were measured with a Bruker Nonius X8Apex equipped with a $4 \mathrm{~K}$ CCD detector using graphite monochromated Mo-K $\alpha$ radiation $\left(\lambda=0.71073 \AA, 2 \theta<55^{\circ}\right) .4685$ independent reflections $(R($ int $)=0.0466)$ were used for the solution and refinement of the structure. The semiempirical absorption correction was applied using intensities of equivalent reflections (SADABS) ${ }^{[3]}$ The structure was solved by the direct method ${ }^{[4]}$ and refined by full-matrix least squares against $F^{2}$. Non-hydrogen atoms were found on difference Fourier maps and refined with anisotropic displacement parameters (except for solvate dichloromethane molecules). The positions of hydrogen atoms were calculated and included in the refinement in isotropic approximation by the riding model. The solvate dichloromethane molecules were refined with restrained $\mathrm{C}-\mathrm{Cl}$ bond lengths. The final convergence factors were $R_{l}(F)=0.1004$ and $w R_{2}=0.3068$ for 4130 reflections with $I>2 \sigma(I)$. Goodness-of-fit $\left(F^{2}\right)=1.537$ for all reflections included in the last stage of refinement. All calculations were made using the SHELXTL-97program package ${ }^{[5]}$ CCDC reference number is 866037.

Insufficient quality of the diffraction data did not provide the unequivocal localization of the oxygen atom in the tetrahydrofuryl substituent. Use of the model of the merohedral twinning did not improve the refinement and afforded the statistically senseless Flack parameter of $-0.0001(0.73)$. Therefore, no twinning model was used in the final refinement stage.

\section{Results and Discussion}

The free-radical substitution in the dichloroclathrochelate precursor $\mathrm{FeBd}_{2}\left(\mathrm{Cl}_{2} \mathrm{Gm}\right)(\mathrm{BF})_{2}$ with tetrahydrofuran radicals can be initiated by different radical initiators both in an inert atmosphere (Table 2) and in air; a typical synthetic procedure is given in the Experimental section. The monotetrahydrofuryl substituted clathrochelate $\mathrm{FeBd}_{2}(\mathrm{Cl}(\mathrm{THF}) \mathrm{Gm})(\mathrm{BF})_{2}$ was obtained in a good yield by the reflux of the macrobicyclic precursor in tetrahydrofuran in the presence of tert-butylhydroperoxide as a radical initiator. The benzoyl peroxide and 1,1'-azo-bis(cyclohexane-1carbnitrile) (VAZO catalyst 88) also can be used as the radical initiators (Table 2). Moreover, the reaction studied proceeds in air, and this suggests that the dichloroclathrochelate precursor $\mathrm{FeBd}_{2}\left(\mathrm{Cl}_{2} \mathrm{Gm}\right)(\mathrm{BF})_{2}$ successfully competes as a radical scavenger with air oxygen for the tetrahydrofuryl radicals formed. The results of the experiments in an inert atmosphere with substoichiometric amounts of radical initiators showed that this reaction has a chain character, and its average propagation length is approximately 2.5 .

Table 2. The yields of the monotetrahydrofuryl-containing macrobicycle $\mathrm{FeBd}_{2}(\mathrm{Cl}(\mathrm{THF}) \mathrm{Gm})(\mathrm{BF})_{2}$ and the average propagation length in the reactions of the dichloroclathrochelate precursor $\mathrm{FeBd}_{2}\left(\mathrm{Cl}_{2} \mathrm{Gm}\right)(\mathrm{BF})_{2}$ with tetrahydrofuran initiated by different radical initiators ([initiator] $=10 \mathrm{~mol} \%$, reflux in argon atmosphere for $3 \mathrm{~h}$ )

\begin{tabular}{cccc}
\hline Initiator & $\begin{array}{c}\text { Yield, } \\
\%\end{array}$ & $\begin{array}{c}\text { Unreacted } \\
\text { precursor, } \\
\%\end{array}$ & $\begin{array}{c}\text { Average } \\
\text { propagation } \\
\text { length }\end{array}$ \\
\hline tert-BuOOH & 29 & 65 & 1.5 \\
BzOOBz & 39 & 60 & 2 \\
$(\mathrm{CN}) \mathrm{C}_{6} \mathrm{H}_{4} \mathrm{NNC}_{6} \mathrm{H}_{4}(\mathrm{CN})$ & 58 & 40 & 2.5 \\
\hline
\end{tabular}

The molecular structure of the clathrochelate $\mathrm{FeBd}_{2}(\mathrm{Cl}(\mathrm{THF}) \mathrm{Gm})(\mathrm{BF})_{2}$ in solution was studied by the one- and two-dimensional ${ }^{1} \mathrm{H}$ and ${ }^{13} \mathrm{C}$ NMR spectroscopies (Figures 1-5, the atom labeling is shown in Scheme 1). As it can be seen from the ${ }^{1} \mathrm{H}$ and COSY NMR spectra, this macrobicyclic molecule contains two independent spin subsystems: the first one is formed by the aromatic protons with the total integral intensity of $20 \mathrm{H}$ (multiplet at $\delta_{\mathrm{H}}=7.38 \mathrm{ppm}$ ), whereas the second one with the total intensity of $7 \mathrm{H}$ is formed by the spin-coupled ${ }^{1} \mathrm{H}$ atoms. A set of the signals with the total intensity of $4 \mathrm{H}$ in the range $2.0-2.5 \mathrm{ppm}$ is characteristic of the aliphatic protons of the alkyl chain bounded to an electron-withdrawing group (atom). The HSQC spectrum clearly demonstrated that these four protons were coupled with two carbon atoms at 27.30 and $30.88 \mathrm{ppm}$. Thus, the hydrogen atoms at these aliphatic groups of $\mathrm{FeBd}_{2}(\mathrm{Cl}(\mathrm{THF}) \mathrm{Gm})(\mathrm{BF})_{2}$ are chemically nonequivalent and have the different chemical shifts, and this may be explained by the presence of a chiral center nearby. As it can be seen from the HSQC spectrum, two signals with the total integral intensity of $2 \mathrm{H}$ in the range $4.0-4.2 \mathrm{ppm}$ belong to the hydrogen atoms attached to the same carbon 
atom. These $\delta_{H}$ values are characteristic of the fragments that are directly attached to an ether oxygen atom. The signal in the ${ }^{1} \mathrm{H}$ NMR spectrum at $5.66 \mathrm{ppm}$ correlates with the carbon atom at $73.65 \mathrm{ppm}$ that is not bound to other hydrogen atoms. These $\delta_{\mathrm{H}}$ and $\delta_{\mathrm{C}}$ values are characteristic of a $\mathrm{CH}$ moiety attached to a strong electron-withdrawing group (atom), and this is the $\mathrm{C}^{2} \mathrm{H}$ fragment of the ribbed tetrahydrofuryl substituent at the macrobicyclic framework. This conclusion is supported by analogous spectral pattern observed earlier for the 1,4-dioxanyl-substituted iron(II) clathrochelate ${ }^{[1]}$ and the ${ }^{1} \mathrm{H}-{ }^{13} \mathrm{C}$ HMBC spectrum used for the study of the longrange ${ }^{1} \mathrm{H}-{ }^{13} \mathrm{C}$ interactions (vide infra).
The ${ }^{13} \mathrm{C}$ NMR spectrum of the clathrochelate obtained contains the above-mentioned four carbon signals of the tetrahydrofuryl fragment as well as the signals of the phenyl substituents in the two benzildioximate chelate fragments. These signals were assigned using both the ${ }^{1} \mathrm{H}-{ }^{13} \mathrm{C}$ HSQC spectrum and the data for its clathrochelate analogs described earlier. ${ }^{[6,7]}$ Four signals of the azomethine carbons of the phenyl-containing $\alpha$-dioximate fragments are observed in the low-field region, whereas the signal of the chlorinecontaining donor oxime group in the ${ }^{13} \mathrm{C}$ NMR spectra usually appears in the range $130-135 \mathrm{ppm}^{[1,7-9]}$ in the case of the synthesized clathrochelate it is observed at $132.28 \mathrm{ppm}$. As

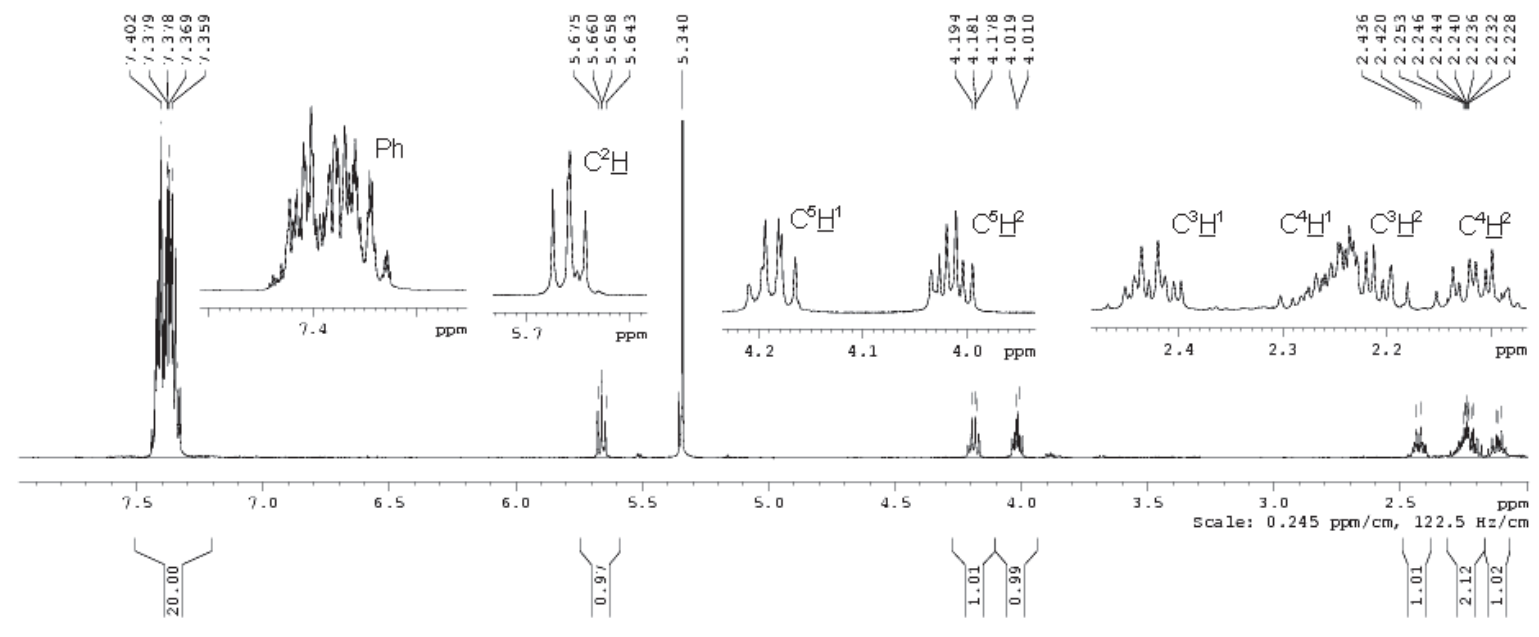

Figure 1. ${ }^{1} \mathrm{H}$ NMR spectrum of the clathrochelate $\mathrm{FeBd}_{2}(\mathrm{Cl}(\mathrm{THF}) \mathrm{Gm})(\mathrm{BF})_{2}$.

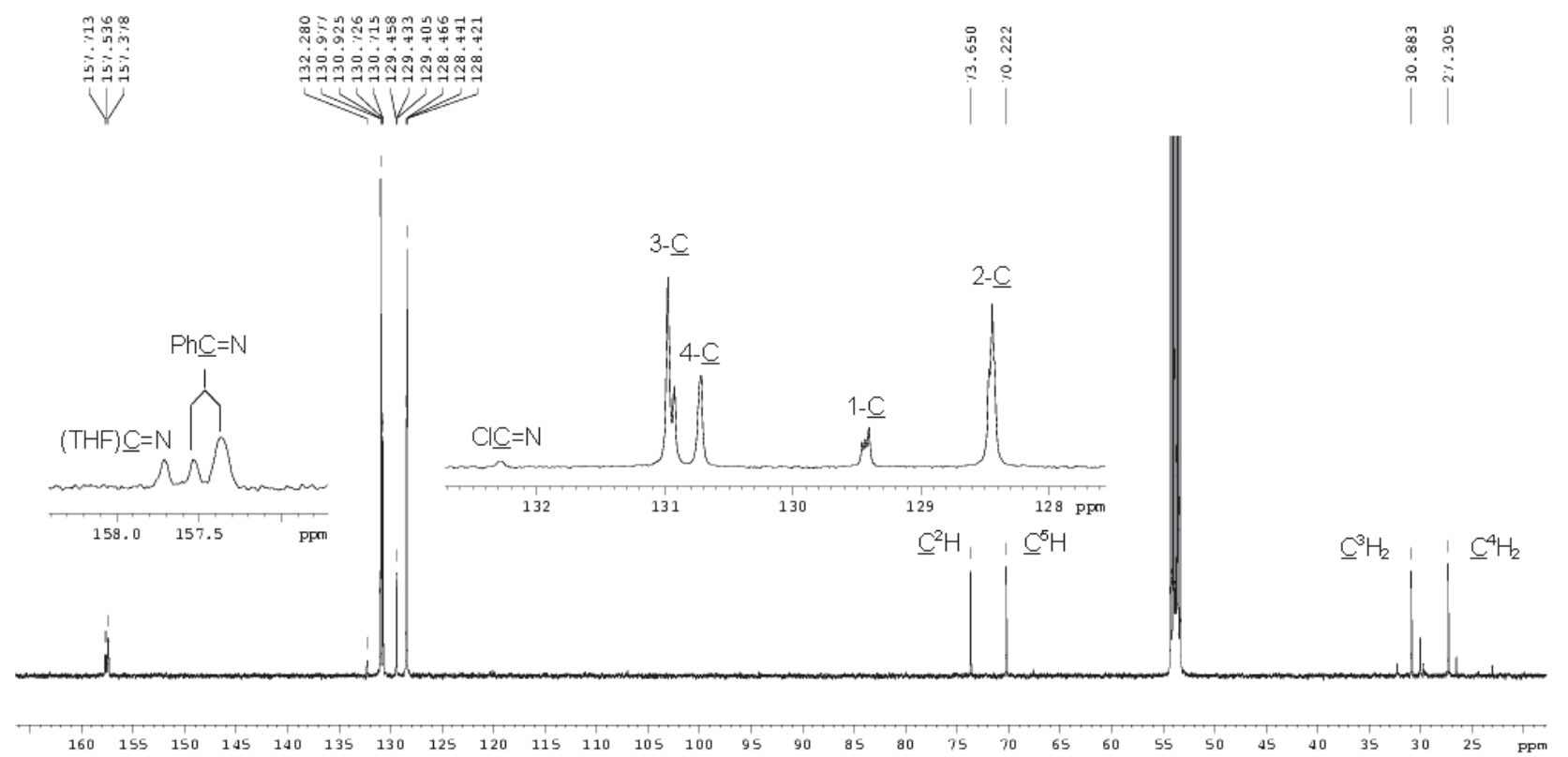

Figure 2. ${ }^{13} \mathrm{C}\left\{{ }^{1} \mathrm{H}\right\}$ NMR spectrum of the clathrochelate $\mathrm{FeBd}_{2}(\mathrm{Cl}(\mathrm{THF}) \mathrm{Gm})(\mathrm{BF}){ }_{2}$. 


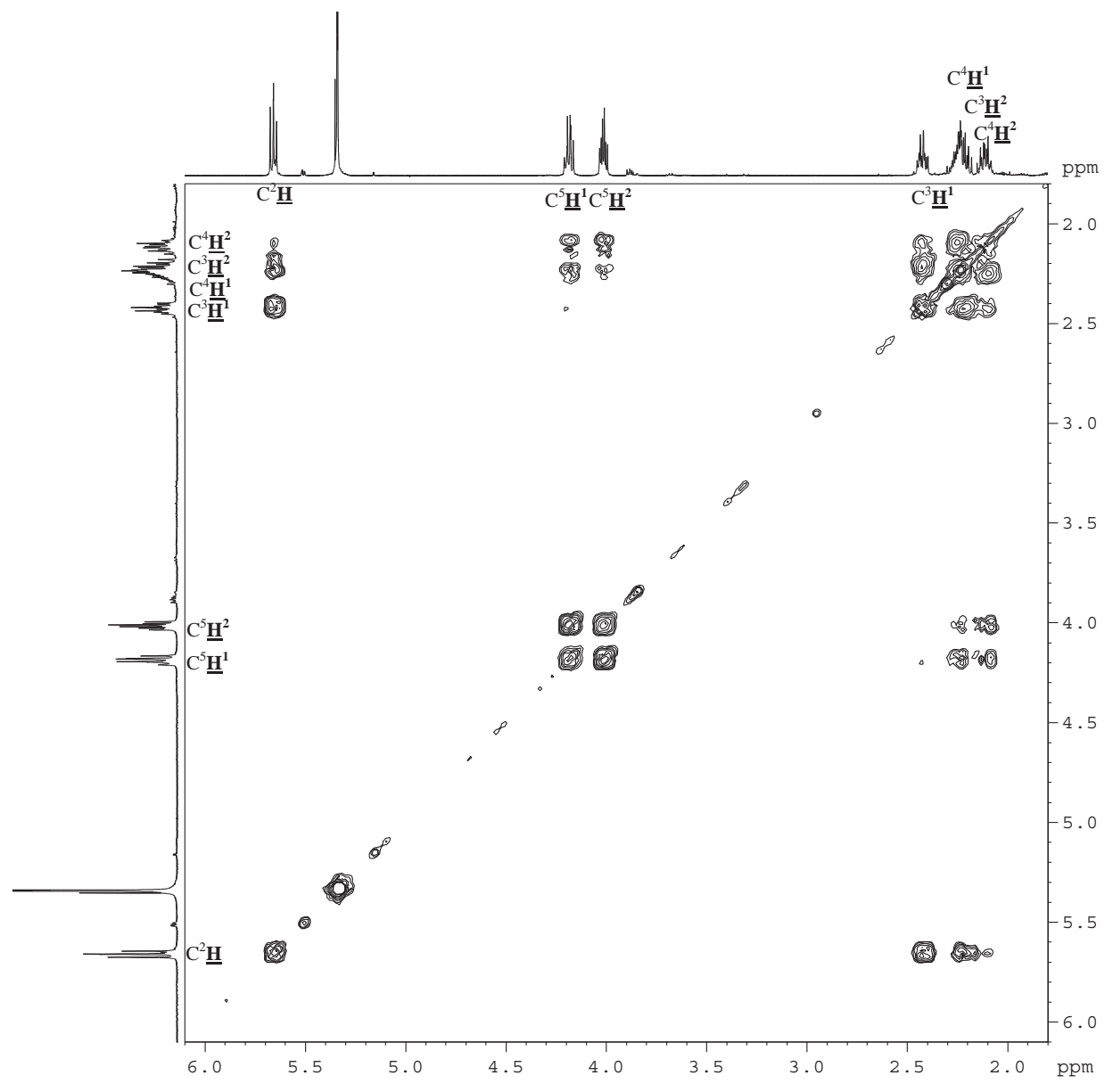

Figure 3. COSY NMR spectrum of the clathrochelate $\mathrm{FeBd}_{2}(\mathrm{Cl}(\mathrm{THF}) \mathrm{Gm})(\mathrm{BF})_{2}$.

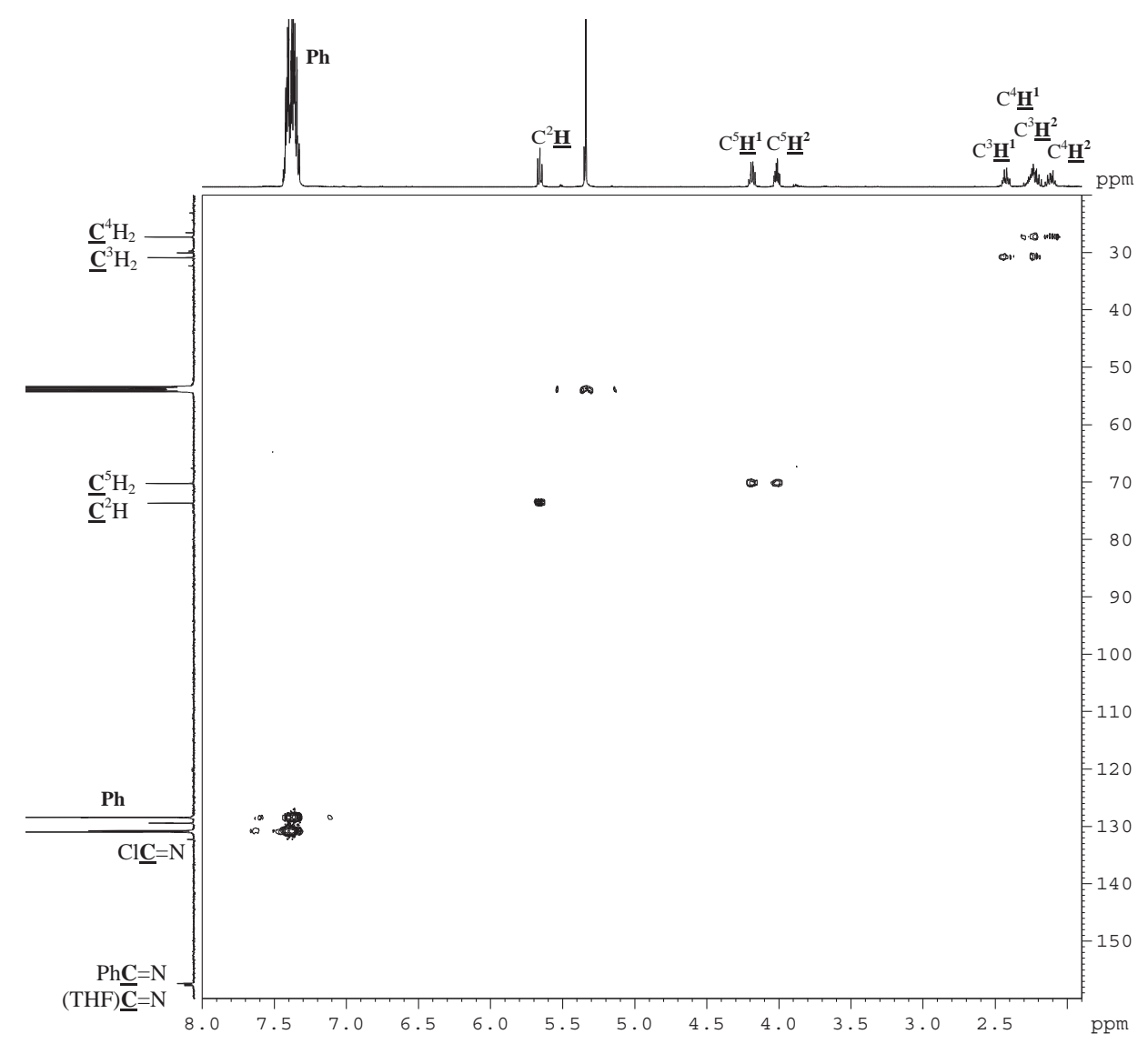

Figure 4. ${ }^{1} \mathrm{H}-{ }^{13} \mathrm{C}$ HSQC NMR spectrum of the clathrochelate $\mathrm{FeBd}_{2}(\mathrm{Cl}(\mathrm{THF}) \mathrm{Gm})(\mathrm{BF})_{2}$. 


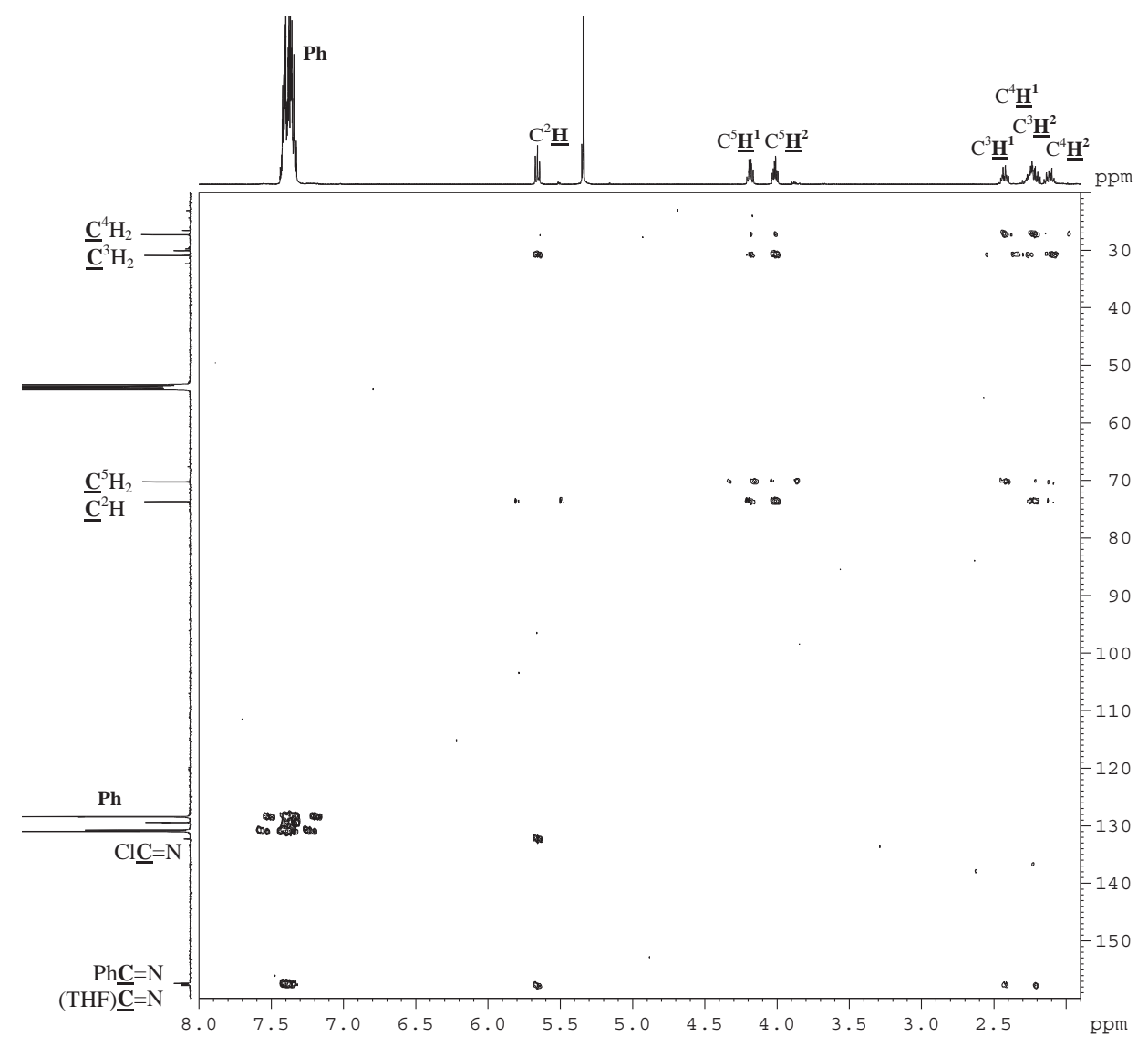

Figure 5. ${ }^{1} \mathrm{H}-{ }^{13} \mathrm{C} \mathrm{HMBC}$ NMR spectrum of the clathrochelate $\mathrm{FeBd}_{2}(\mathrm{Cl}(\mathrm{THF}) \mathrm{Gm})(\mathrm{BF})_{2}$.

it can be seen from the HMBC spectrum, the signals with $\delta_{\mathrm{C}}$ of approximately 157 ppm belong to the azomethine carbon atoms of both benzildioximate chelate moieties (at 157.38 and $157.53 \mathrm{ppm}$ ) and the tetrahydrofuryl-substituted donor oxime group (at $157.71 \mathrm{ppm}$ ). A large number of the signals in this ${ }^{13} \mathrm{C}\left\{{ }^{1} \mathrm{H}\right\}$ NMR spectrum assigned to the phenyl and azomethine carbon atoms indicates an absence of the symmetry plane passing through the middles of the chelate $\mathrm{C}-\mathrm{C}$ bonds in the $\alpha$-dioximate ribbed fragments of the macrobicyclic molecule and the encapsulated iron(II) ion. The ${ }^{11} \mathrm{~B}$ and ${ }^{19} \mathrm{~F}$ NMR spectra also clearly showed the non-equivalence of the capping $\mathrm{O}_{3} \mathrm{BF}$ fragments of this molecule.

A valuable information about the molecular structure of the clathrochelate $\mathrm{FeBd}_{2}(\mathrm{Cl}(\mathrm{THF}) \mathrm{Gm})(\mathrm{BF})_{2}$ was obtained from its ${ }^{1} \mathrm{H}-{ }^{13} \mathrm{C}$ HMBC spectrum. As it was mentioned above, the signals at $5.66 \mathrm{ppm}$ in ${ }^{1} \mathrm{H}$ NMR and at $73.65 \mathrm{ppm}$ in ${ }^{13} \mathrm{C}$ NMR spectra, as well as the corresponding doublet in the $\mathrm{HMBC}$ spectrum, belong to the $\mathrm{C}^{2} \mathrm{H}$ group of the ribbed tetrahydrofuryl substituent that is inherently bound to the functionalized $\alpha$-dioximate chelate fragment. The hydrogen atom of this group has long-range interactions with the carbon atom of the tetrahydrofuryl-containing donor oxime group (the cross-peak at $157.71 \mathrm{ppm}$ ) and that of the $\mathrm{Cl}-\mathrm{C}=\mathrm{N}$ one (the cross-peak at $132.28 \mathrm{ppm}$ ); the cross-peak at $30.88 \mathrm{ppm}$ was assigned to its interaction with the methylene unit $\mathrm{C}^{3} \mathrm{H}_{2}$. The latter is coupled both with the other methylene units of the tetrahydrofuryl substituent and with the azomethine carbon atom $\left(\delta_{\mathrm{C}}=157.71 \mathrm{ppm}\right)$.

Thus, these 1D and 2D NMR spectra confirmed the bonding of the functionalizing tetrahydrofuryl substituent to the clathrochelate framework through the $\mathrm{C}^{2}$ atom. Hence, the reaction studied has a high regioselectivity. This result may be explained by the stabilization of the tetrahydrofur-2yl radical by the adjacent heteroatom. ${ }^{[10]}$

The molecular structure of the clathrochelate $\mathrm{FeBd}_{2}(\mathrm{Cl}(\mathrm{THF}) \mathrm{Gm})(\mathrm{BF})_{2}$ in the solid state was obtained from a single-crystal $\mathrm{X}$-ray diffraction experiment. In the crystal of $\mathrm{FeBd}_{2}(\mathrm{Cl}(\mathrm{THF}) \mathrm{Gm})(\mathrm{BF})_{2} \cdot 2.2 \mathrm{CH}_{2} \mathrm{Cl}_{2}$, the solvate dichloromethane molecules partially occupy three positions. The macrobicyclic molecule $\mathrm{FeBd}_{2}(\mathrm{Cl}(\mathrm{THF}) \mathrm{Gm})$ $(\mathrm{BF})_{2}$ has a chiral center at the bridging $\mathrm{C}^{2}$ atom, and the studied complex crystallizes in a chiral space group $P 2{ }_{1}{ }_{2} 2_{1}$. Therefore, its single crystal should contain only one of the two possible enantiomers. However, a poor quality of the bestavailable single crystal did not allow making unequivocal conclusions.

The clathrochelate molecule $\mathrm{FeBd}_{2}(\mathrm{Cl}(\mathrm{THF}) \mathrm{Gm})$ $(\mathrm{BF})_{2}$ (Figure 6) has a distorted trigonal-prismatic geometry characteristic of the boron-capped tris-dioximate iron(II) clathrochelates: ${ }^{[9]}$ the average distortion angle $\phi$ of the $\mathrm{FeN}_{6}$ coordination polyhedron is equal to $26.6^{\circ}\left(\phi=0^{\circ}\right.$ for an ideal trigonal prism; $\phi=60^{\circ}$ for a trigonal antiprism), and the height $h$ of this polyhedron is approximately $2.34 \AA$. The Fe-N distances and the bite angles $\alpha$ (half of the chelate angles N-Fe-N) also have the typical values (1.871(10) 1.933(12) $\AA$ and 39.4(3) - 40.4(4) ${ }^{\circ}$, respectively).

The functionalizing tetrahydrofuryl substituent has an envelope conformation: its three carbon atoms and one oxygen atom (the oxygen position proved by NMR) are located in one plane (their deviations from the mean plane do 


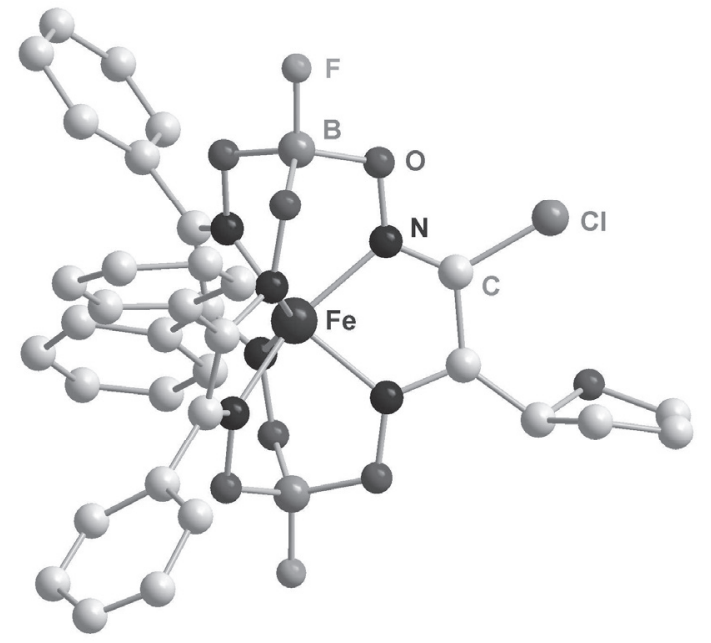

Figure 6. General view of the clathrochelate $\mathrm{FeBd}_{2}(\mathrm{Cl}(\mathrm{THF}) \mathrm{Gm})(\mathrm{BF})_{2}$. Hydrogen atoms are omitted for clarity.

not exceed $0.03 \AA$ ), whereas the bridging $\mathrm{C}^{2}$ atom deviates from this plane by $0.48 \AA$.

\section{Conclusions}

The free-radical substitution of the iron(II) dichloroclathrochelate precursor with radical tetrahydrofuran derivatives afforded the monofunctionalized tetrahydrofurylcontaining macrobicyclic complex, this substitution occuring via the $\mathrm{C}^{2}$ atom of the tetrahydrofuryl moiety. The reaction studied has a high regioselectivity; the total yield of the clathrochelate complexes isolated after this reaction (the sum of the precursor $\mathrm{FeBd}_{2}\left(\mathrm{Cl}_{2} \mathrm{Gm}\right)(\mathrm{BF})_{2}$ and the only resulting macrobicycle $\left.\mathrm{FeBd}_{2}(\mathrm{Cl}(\mathrm{THF}) \mathrm{Gm})(\mathrm{BF})_{2}\right)$ is approximately $95-98 \%(100 \%$ corresponds to the initial amount of the dichloroclathrochelate precursor). This result was explained by the stabilization of the tetrahydrofur-2-yl radical by the adjacent oxygen atom.

Acknowledgement. This study was supported by RFBR grants No 10-03-00403, 11-03-90458, 12-03-00961, 12-0390706 and 12-03-90431. The authors are indebted to Dr. N. Kuratieva (NIIC SB RAS) for obtaining the single-crystal $\mathrm{X}$-ray diffraction data. I.V.E. is grateful to Carl Zeiss AG for financial support.

\section{References}

1. Vershinin M.A., Burdukov A.B., Eltsov I.V., Reznikov V.A., Boguslavsky E.G., Voloshin Y.Z. Polyhedron 2001, 30, 12331237.

2. Voloshin Y.Z., Zavodnik V.E., Varzatskii O.A., Belsky V.K., Palchik A.V., Strizhakova N.G., Vorontsov I.I., Antipin M.Y. Dalton Trans. 2002, 1193-1202.

3. Bruker AXS Inc., APEX2 (Version 1.08), SAINT (Version 7.03), and SADABS (Version 2.11). Bruker Advanced X-ray Solutions, Madison, Wisconsin, USA, 2004.

4. Burla M.C., Caliandro R., Camalli M., Carrozzini B., Cascarano G.L., De Caro L., Giacovazzo C., Polidori G., Spagna R. J. Appl. Cryst. 2005, 38, 381-388.

5. Sheldrick G.M. Acta Cryst. 2008, A64, 112-122.

6. Vershinin M.A., Burdukov A.B., Boguslavskii E.G., Pervukhina N.V., Kuratieva N.V., Eltsov I.V., Reznikov V.A., Varzatskii O.A., Voloshin Y.Z., Bubnov Y.N. Inorg. Chim. Acta 2011, 366, 91-97.

7. Burdukov A.B., Vershinin M.A., Pervukhina N.V., Kozlova S.G., Eltsov I.V., Voloshin Y.Z. Russ. Chem. Bull. 2011, 24552460 .

8. Voloshin Y.Z., Kostromina N.A., Krämer R. Clathrochelates: Synthesis, Structure and Properties. Amsterdam: Elsevier, 2002. $420 \mathrm{p}$.

9. Burdukov A.B., Vershinin M.A., Eltsov I.V., Pervukhina N.V., Voloshin Y.Z. Inorg. Chem. Comm. 2009, 12, 919-922.

10. Zipse H. Top. Curr. Chem. 2006, 263, 163-189. 